University of Nebraska - Lincoln

DigitalCommons@University of Nebraska - Lincoln

Faculty Publications, Department of Psychology

Psychology, Department of

August 2006

\title{
Participant responses to retrospective surveys of child maltreatment: Does mode of assessment matter?
}

\author{
David DiLillo \\ University of Nebraska-Lincoln, ddilillo@unl.edu \\ Sarah DeGue \\ University of Nebraska-Lincoln \\ Amanda Kras \\ University of Nebraska-Lincoln \\ Andrea R. Di Loreto-Colgan \\ University of Nebraska-Lincoln \\ Cindy Nash \\ University of Nebraska-Lincoln
}

Follow this and additional works at: https://digitalcommons.unl.edu/psychfacpub

Part of the Psychiatry and Psychology Commons

DiLillo, David; DeGue, Sarah; Kras, Amanda; Di Loreto-Colgan, Andrea R.; and Nash, Cindy, "Participant responses to retrospective surveys of child maltreatment: Does mode of assessment matter? " (2006). Faculty Publications, Department of Psychology. 122.

https://digitalcommons.unl.edu/psychfacpub/122

This Article is brought to you for free and open access by the Psychology, Department of at DigitalCommons@University of Nebraska - Lincoln. It has been accepted for inclusion in Faculty Publications, Department of Psychology by an authorized administrator of DigitalCommons@University of Nebraska - Lincoln. 


\title{
Participant Responses to Retrospective Surveys of Child Maltreatment: Does Mode of Assessment Matter?
}

\author{
David DiLillo, $\mathrm{PhD}$ \\ Sarah DeGue, PhD \\ Amanda Kras, MA \\ Andrea R. Di Loreto-Colgan, MA \\ Cindy Nash, $\mathrm{PhD}$ \\ University of Nebraska-Lincoln
}

\begin{abstract}
This study examines the impact that different methods of assessing child maltreatment history may have on adult participants. A total of 334 female undergraduate students were randomly assigned to complete a retrospective measure of child sexual and physical abuse in one of three conditions: paper-and-pencil questionnaire, face-to-face interview, or computer-administered survey. Disclosure rates of abuse, psychological distress and mood change, preferences for assessment format, and perceptions of confidentiality were examined across the three assessment formats. Although disclosure did not vary by condition, participants with a history of abuse reported more distress and mood change than did nonvictims, particularly in the computer condition. Nevertheless, the computer condition was rated as the most preferred format and was viewed by participants as the most confidential means of assessing maltreatment history. Participants reporting abuse through interviews were more likely than those in other conditions to state a preference for another type of assessment format. The implications of these findings for abuse history research are discussed.
\end{abstract}

Keywords: child maltreatment, computer assessment, mode of administration has relied heavily on the use of retrospective measures to identify individuals with a history of victimization. In general, this approach involves asking adults to indicate whether, and to what degree, they experienced various forms of maltreatment during childhood. Traditionally, the most common methods of eliciting this information have been interviews (either face-to-face or, less commonly, telephone) and paper-and-pencil surveys. These measures contain a variety of sensitive questions about abusive acts participants may have endured as children. In the case of sexual abuse, for example, a participant might be asked to respond to questions such as, "When you were a child, were you ever forced to have sexual intercourse against your will?" In the case of physical abuse, participants may encounter questions such as, "My parent beat me by slapping, hitting and/or punching me repeatedly" (True/ False). In both cases, an affirmative response may be followed by more detailed queries about 
the perpetrator's identity as well as the specific nature, frequency, and duration of the acts that occurred. In light of the traumatic nature of child maltreatment, as well as the detailed and graphic content of these self-report measures, it is important to consider the impact that participation in such surveys may have upon individuals with a history of abuse. Some have wondered, for example, whether those with a history of maltreatment may become seriously distressed or "revictimized" as a result of participating in surveys about abuse (Walker, Newman, Koss, \& Bernstein, 1997). Institutional review boards, in particular, are often concerned with the potential effects of these surveys on the emotional well-being of participants (Walker et al., 1997). Thus, a thorough understanding of the impact of surveys on participants is important to the sensitive planning and execution of abuse history research.

\section{IMPACT OF RETROSPECTIVE SURVEYS OF ABUSE ON PARTICIPANTS}

Despite innumerable studies relying on retrospective reports of abuse, relatively few in-vestigations have explored the emotional impact these surveys may have on participants. In an initial study, Walker et al. (1997) found that many women reported positive reactions to completing a detailed abuse history assessment, but that a small proportion (13\%) perceived the experience to be more upsetting than they had expected. Although women with a history of abuse were more likely to report such reactions, only 4 of 327 total participants regretted taking part in the study. In a follow-up investigation that used a similar questionnaire, as well as subsequent interviews with those identified as abuse survivors, Newman, Walker, and Gefland (1999) once more found that, while many women felt they had benefited from their participation, a small number (10.5\%) experienced unanticipated emotional distress resulting from the assessment. Again, distress was highest for those identified as having been sexually abused compared to those who reported either nonsexual forms of abuse or no abuse at all. Although maltreatment severity was associated with greater upset, these researchers reported that, overall, "even the highest group was more neutral than anything." Only 5\% of women regretted participating in the study, which again suggests that unexpected upset did not often result in regret about participating. Notably, participants reported more benefit and less regret in response to the interview format than the paper-and-pencil questionnaire. Martin, Perrott, Moms, and Romans (1999) examined the long-term correlates of participation in child sexual abuse research and found that, when asked about their reactions to an abuse history interview that had occurred an average of six years earlier, survivors recalled being "moderately" comfortable talking about their early maltreatment experiences. However, abuse survivors were 10 times more likely than abused women to view the initial interview as a positive experience, suggesting that they derived some benefit from the experience. Finally, in contrast to the above trends, one study of inpatient psychiatric patients' reactions to an interview about childhood sexual abuse, physical abuse, and other traumas revealed that $24 \%$ of participants rated themselves as very much or extremely upset by completing the interview (Carlson et al., 2003). Another $6.6 \%$ did not complete the interview because they were upset by it.

The above findings provide initial data regarding the degree to which retrospective surveys are perceived as distressing or beneficial by adult survivors of maltreatment. In general, studies suggest that many women perceive benefit from their involvement in abuse history research. In addition, although a minority of participants experience unexpected upset, in rela- 
tively few cases do women regret participating. Psychiatric inpatients, however, may be an exception to such trends, with available data suggesting that these individuals experience greater levels of distress and regret related to their involvement in retrospective abuse surveys.

\section{MODE OF ADMINISTRATION}

Despite knowledge gained from this research, we still have an incomplete understanding of the various factors that impact participants' responses to abuse history research. An important unanswered question is whether the methods used to gather information about early maltreatment have a bearing on respondents' willingness to disclose abuse or their reactions to participation. For example, compared to in-person interviews, questionnaires provide anonymity and perhaps an increased sense of confidentiality, which may reduce participant distress and facilitate disclosure. On the other hand, disclosure during interviews may be promoted through understanding and support on the part of the interviewer. Conversely, disclosure may be hampered in interviews if participants are reluctant to reveal sensitive information to someone they just met. This latter possibility is supported by data from the public health arena, which show that the reporting of other types of sensitive information, such as alcohol and drug use, is greater in response to self-administered questionnaires than to direct questioning from interviewers (Aquilino 1994; Schober, Fe Caces, Pergamit, \& Branden, 1992; Turner, Lessler, \& Devore, 1992). Nevertheless, interviews offer the ability to probe ambiguous responses (Fry, Rozewicz, \& Crisp, 1996; Wyatt \& Peters, 1986), whereas questionnaires must employ contingent questioning and complex branching or skip patterns in order to capture the varying circumstances of each person's abuse history. This type of structure can be difficult for respondents to follow and may result in missing or inaccurate data (Lessler \& Holt, 1987). Nevertheless, from the researcher's perspective, questionnaires are a more efficient means of data collection because they can be group-administered and do not require training interviewers.

In one of the few studies addressing participant reactions to different modes of data collection, Newman et al. (1999) assessed abuse history via both interview and questionnaire formats in a sample of community women and reported that participants responded more favorably to interviews. However, this finding may not have been attributable only to mode of administration, for it appears that the specific questions used to assess sexual abuse also differed across the two assessment formats. Other authors have asserted that interviews elicit more complete reporting of past abuse (Wyatt \& Peters, 1986). Unfortunately, this claim was based on a comparison of only four studies, which again differed in ways other than data collection method (e.g., definition of sexual abuse, sample composition, wording of screening questions). Martin, Anderson, Romans, Mullen, and O'Shea (1993) mailed a self-administered sexual abuse questionnaire to a large sample of New Zealand women and later assessed abuse history again via interview with a subset of the original sample. These researchers found that more instances of abuse were reported during interviews but that serious episodes committed by close family members were more often reported in response to the questionnaire. However, because measures in this study were completed in a set sequence (questionnaire then interview), it is impossible to rule out the influence of order effects. An additional concern is that the abuse screeners contained in the questionnaire format were less specific - and thus potentially less sensitive - than those used in the interview format. 


\section{COMPUTER-BASED ASSESSMENT}

In addition to more traditional modes of assessment (i.e., face-to-face interviews and paperand-pencil questionnaires), investigators have recently begun to employ computer-based instruments as a means of inquiring about potentially sensitive topics, including child maltreatment (Abbey, BeShears, Clinton-Sherrod, \& McAuslan, 2004; Nash, DiLillo, MessmanMoore, \& Rinkol, 2002). Computerized instruments can be programmed to execute skip patterns, check for out-of-range responses and inconsistencies across similar questions, and generate data files instantly, thereby eliminating the need for complex instructions and contingent questioning patterns that can be confusing to participants. Further, much like questionnaires, computerized administration can occur in private, which may increase perceptions of confidentiality and willingness to disclose. Some authors have suggested that computer-administered questionnaires convey a greater sense of confidentiality than do paper-and-pencil questionnaires and therefore may increase reporting of sensitive information (Tourangeau \& Smith, 1996; Turner et al., 1996). In support of this, studies of various health risk behaviors (e.g., sexual practices, drug use) have found that students prefer computer-based questionnaires to the print variety and feel more "openness" when responding to questions in a computerized format (Maitland \& Mandel, 1994). In assessing sensitive sexual behaviors, computer-based assessments may also be less susceptible than interviews to socially desirable responding (Kissinger et al., 1999). Despite these related findings, no studies to date have directly compared participants' reactions to a computer-based abuse history measure relative to more traditional interview and paper-and-pencil approaches.

\section{THE PRESENT STUDY}

The present study seeks to expand current knowledge about reactions to participation and rates of reported abuse in response to three different modes of retrospective data collection. More specifically, we sought to address the following research questions:

1. Is mode of administration related to likelihood of disclosing abuse? That is, do disclosure rates differ between those who complete questionnaire, interview, or computer-based assessments?

2. How much distress do participants report in response to completion of abuse history measures?

3. What is the impact of victim status and mode of administration on participant distress? Relatedly, for victims only, is mode of administration associated with participant distress?

4. Apart from distress, do participants express a preference for a particular mode of administration? Do these preferences vary by victim status?

5. Finally, do perceptions of confidentiality vary according to mode of administration?

In order to most effectively address these questions, we employed an experimental design in which participants were randomly assigned to complete a recently developed abuse history measure, the Computer Assisted Maltreatment Inventory (CAMI; Nash et al., 2002) in one 
of three conditions: paper-and-pencil questionnaire, face-to-face interview, or computer-based administration. In addition to its randomized design, a methodological strength of the study is that all versions of the CAMI were identical in question content and order; only mode of administration varied between groups. Responses to participation were assessed via a feedback questionnaire administered following completion of the CAMI. Finally, given the hundreds of investigations examining abuse history among college students (cf. Rind, Tromovitch, \& Bauserman, 1998) it is especially important to understand the impact of participation on this group. Thus, this study was conducted using an undergraduate population.

\section{METHOD}

\section{Participants}

Participants consisted of 334 female undergraduate students from a large midwestern university. Their age at participation ranged from 17.97 to 42.72 years, with a mean of 20.00 years $(S D=2.52)$. The majority of participants were White $(89.8 \%)$. However, African Americans (2.4\%), Asian Americans (2.4\%), Hispanic Americans (1.8\%), Native Americans $(0.3 \%)$, and other ethnicities $(2.1 \%)$ were also included in the sample. Most participants reported having never been married (95.8\%). Participants reported a wide range of family incomes while growing up. The most frequently endorsed income bracket, however, was $\$ 41,000-\$ 70,000$, which places the largest group of participants at the middle-class level of socioeconomic status $(35.9 \%)$.

\section{Measures}

Child Maltreatment History. All participants completed the Computer Assisted Maltreatment Inventory (CAMI; Nash et al., 2002), a computer-based self-report measure that assesses participants' history of childhood maltreatment, including sexual abuse and physical abuse. The CAMI contains questions assessing: (1) the presence or absence of each form of maltreatment, (2) the key features of all abusive activities reported, and (3) the frequency and severity of the maltreatment. The sexual and physical abuse subscales begin with a series of behaviorally specific screener questions, which are used to identify those who experienced sexual and/ or physical abuse during childhood. Sexual abuse is defined according to three criteria: (1) nonconsensual sexual activity occurring before the age of $18,(2)$ explicitly sexual activity (excluding consensual sex play or exploration) with a close family member before the age of 18 , and (3) sexual activities occurring before the age of 14 with someone five or more years older, or, if the respondent was between the ages of 14 and 17, activities occurring with someone 10 or more years older. Physical abuse is defined as activities occurring with a parent or primary caregiver that involved (1) ever being punched, kicked, choked, beaten, burned, or threatened with a weapon or (2) repeatedly (more than 10 times) being grabbed, shaken, or slapped by a caregiver. Participants who endorse one or more of the screener items, indicating that they meet the criteria for one or both forms of abuse, are then presented with a series of more detailed questions concerning the identity of the perpetrator, nature of the abusive activities, frequency and duration of abuse, and use of force. 
For the purposes of this study, the CAMI was adapted from its original computer-based format into two additional formats: a paper-and-pencil questionnaire and a structured face-toface interview. However, all questions remained identical across the three formats. The original computer-based CAMI is structured such that participants receive and respond to subscales concerning each of the forms of child maltreatment in random order. This randomized presentation of maltreatment subscales was also maintained within the questionnaire and interview formats.

Five female doctoral students in the APA-accredited Clinical Psychology Training program at the University of Nebraska-Lincoln underwent training to administer the CAMI interview in a standardized format. Because sexual abuse was a focus of the interview, participant and interviewer gender were matched. This is consistent with several other studies involving sexual abuse interviews with female participants (e.g., Williams, 1994). Interviewer training occurred in group sessions led by the first author, a licensed clinical psychologist. These sessions included didactic and experiential components (e.g., role plays) focusing on techniques for interviewing trauma survivors, as well as methods of interview standardization. Following training, each interviewer conducted two to three pilot interviews, which were observed by the primary investigator to ensure standardized administration across interviewers.

Feedback Questionnaire. Regardless of their assigned condition, all participants received a feedback questionnaire following completion of the CAMI. This questionnaire assessed participants' thoughts and feelings regarding the CAMI, as well as their preference for a particular mode of administration (i.e., computer, questionnaire, or interview). Contained in this questionnaire were two questions regarding participants' level of distress: (1) "My mood and emotions feel the same now as when I started (the assessment)" and (2) "Answering these questions has left me feeling uneasy or upset." The feedback questionnaire also contained two questions asking participants about the degree to which they would have preferred completing the CAMI in each of the two nonassigned conditions. Thus, for example, those in the questionnaire condition responded to the following items: (1) "I would have preferred to provide this information to an interviewer" and (2) "I would have preferred to provide this information in a computer format, rather than on paper." Finally, participants responded to the following item related to perceptions of confidentiality: "I feel the information I provided will be kept confidential." All items on the feedback questionnaire were rated on a 5-point Likert-type scale ranging from 1 (strongly disagree) to 5 (strongly agree).

\section{Procedures}

Participants were recruited from a research participant pool of students enrolled in psychology courses and were awarded extra credit for participation. After informed consent was provided, participants were randomly assigned to the condition in which they would complete the CAMI (computer, questionnaire, or interview). Once assigned, participants in the computer and questionnaire conditions were taken to private rooms where they completed the assessment materials. Face-to-face interviews were conducted in a university clinic by trained female clinical psychology doctoral students. Following data collection, all participants were debriefed about the purposes of the study and asked about any adverse reactions, including psychological distress. Although no participants reported serious distress, all were provided with the contact information of local agencies that offer mental health services on a sliding fee scale. The study was approved by the University of Nebraska-Lincoln Institutional Review Board. 


\section{RESULTS}

As a result of randomization to conditions, participants were distributed fairly evenly across each mode of administration (computer, $n=112$; questionnaire, $n=114$; interview, $n=108$ ). Results indicated that the three groups were equivalent in terms of age $(\mathrm{F}=1.4, p=.25)$, racial/ethnic background $\left(\chi^{2}=16.2, p=.18\right)$, marital status $\left(\chi^{2}=3.5, p=.75\right)$, and socioeconomic status $\left(\chi^{2}=18.8, p=.66\right)$. Using the CAMI, $19.7 \%(\mathrm{n}=66)$ of the full sample of were categorized as victims of child maltreatment based on a history of child physical abuse $(12.8 \%$, $n=43)$, child sexual abuse $(4.2 \%, n=14)$, or combined physical and sexual abuse $(2.7 \%, n=$ 9). A post hoc power analysis indicated the above tests produced sufficient power (.99) to detect medium effect sizes (.30) in the present sample.

\section{Likelihood of Disclosing by Mode of Administration}

To assess the relationship between mode of administration and likelihood of disclosing abuse, victimization rates were compared across conditions. Disclosure of any maltreatment did not vary significantly across modes of administration, with $7.2 \%$ of victims identified in the questionnaire condition, $6.6 \%$ in the computer condition, and $6 \%$ in the interview condition $\left(\chi^{2}\right.$ $=0.23, p=.89)$. When disclosure rates were examined by type of abuse, the largest proportion of child sexual abuse victims was identified in the computer condition $(3.3 \%, n=11)$, followed by the questionnaire $(2.1 \%, n=7)$ and interview conditions $(1.5 \%, n=5)$. In contrast, the largest proportion of child physical abuse victims was identified in the questionnaire condition $(6.3 \%, n=21)$, followed by the computer $(4.8 \%, n=16)$ and the interview conditions $(4.5 \%, n=15)$. Again, however, differences in disclosure rates across modes did not reach significance for victims of sexual $\left(\chi^{2}=2.5, p=.29\right)$ or physical abuse $\left(\chi^{2}=1.1, p=.58\right)$.

\section{Mood Change and Distress}

As noted, participants responded to two items assessing their level of distress following completion of the CAMI. The first item inquired about possible changes in mood as a result of the assessment, while the second asked whether the assessment resulted in emotional upset or uneasy feelings. Using a response scale from $1=$ strongly disagree to $5=$ strongly agree, overall means indicated that participants generally agreed that their mood and emotions were the same as when they started $(M=3.9, S D=1.2)$ and disagreed that the questions left them feeling upset or uneasy $(M=1.9, S D=1.1)$. However, when examining mood change and distress separately for nonvictims and those with a history of abuse, a greater proportion of abuse victims experienced mood changes or upset resulting from the assessment (see Table 1). More specifically, $50 \%$ of victims either somewhat or strongly disagreed that their mood and emotions were the same as when they started the assessment, while $31.8 \%$ of victims somewhat or strongly agreed that the questions made them uneasy or upset. This compared to $11.2 \%$ and $6.4 \%$ of nonvictims' responses to the same questions, respectively.

\section{Effect of Victim Status and Mode of Administration on Level of Distress}

To examine the effects of victim status (victim and nonvictim) and mode of administration (interview, questionnaire, and computer) on participants' level of distress (change in mood or 
TABLE 1. Distribution (\%) of Distress Ratings by Victim Status

\begin{tabular}{lccc}
\hline & $\begin{array}{c}\text { Nonvictims } \\
(n=268)\end{array}$ & $\begin{array}{c}\text { Victims } \\
(n=66)\end{array}$ & $\chi^{2}(4,326)$ \\
\hline "My mood and emotions are the same as when I started." & & $54.74^{* *}$ \\
Strongly disagree & 1.9 & 9.1 & \\
Somewhat disagree & 9.3 & 40.9 & \\
Neutral & 7.1 & 9.2 & \\
Somewhat agree & 32.1 & 26.2 & $57.49^{* *}$ \\
Strongly agree & 47.0 & 30.8 & \\
& & & \\
"The questions left me feeling upset & or uneasy." & & \\
Strongly disagree & 58.6 & 21.2 & \\
Somewhat disagree & 23.5 & 21.2 & \\
Neutral & 9.0 & 24.2 & \\
Somewhat agree & 4.5 & 22.7 & \\
Strongly agree & 1.9 & 9.1 & \\
\hline
\end{tabular}

Note. Column totals do not equal $100 \%$ due to missing data for $2.6 \%(n=7)$ and $1.5 \%$ $(n=1)$ of participants on these items, respectively.

${ }^{* *} p<.01$.

feelings of upset), two between-groups factorial ANOVAs with follow-up analyses using the LSD procedure $(p=.05)$ were performed. The means and standard deviations for all groups, as well as the ANOVA results, are presented in Table 2. These analyses revealed a main effect for victim status on the first distress-related item, with victims reporting more change in their mood or emotions following participation than did nonvictims, $F(1,320)=64.62, p<.01$. There was no main effect for mode of administration and no interaction between victim status and mode of administration in terms of participants' mood stability during participation.

As indicated in Table 2, there was also a main effect for victim status on the second distress-related item, with victims reporting greater upset or unease in response to completing the CAMI, $F(1,320)=64.1, p<.01$. Although no main effect was found for mode of administration for this item, a significant interaction was identified between victim status and mode of administration as they relate to level of upset, $F(2,320)=3.45, p=.03$. The pattern of this interaction indicated that, for victims, the computer condition was related to greater upset than either the interview or questionnaire conditions, which were equivalent. In contrast, for nonvictims, level of upset was equivalent across all modes of administration (LSD minimum mean difference $=0.39$ ). That is, mode of administration was only related to increased levels of upset for victims in the computer condition. For nonvictims and victims in other conditions, mode of administration did not affect the level of upset experienced.

\section{Mode of Administration Preference by Victim Status}

As noted, participants were asked whether they would have preferred completing the assessment in each of the other conditions, with preferences for another mode of administration rated on a scale from $1=$ strongly disagree to $5=$ strongly agree. Preference ratings for each 


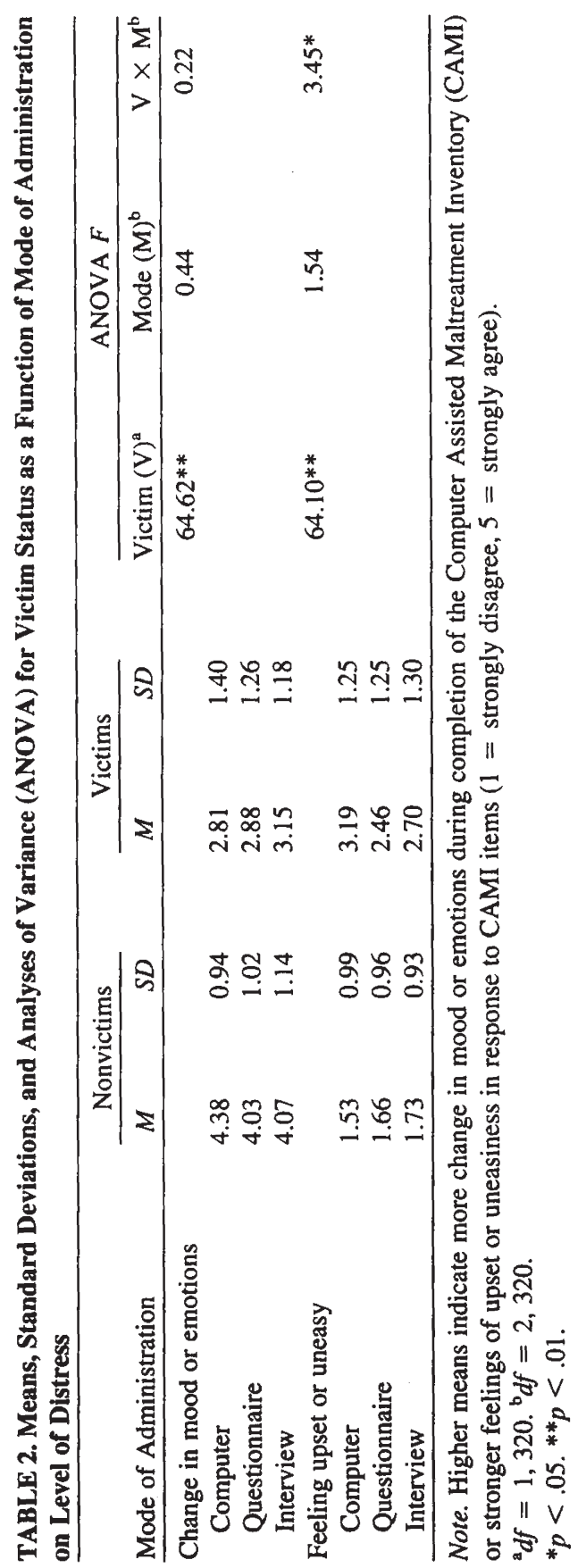


of the other two assessment types were then averaged, yielding a score summarizing respondents' preference for a condition other than the one to which they were assigned.

To examine the effects of victim status (victim and nonvictim) and mode of administration (interview, questionnaire, and computer) on participants' preferences for completing the assessment in another condition, a between-groups factorial ANOVA with follow-up analyses using the LSD procedure $(p=.05)$ was performed. Means, standard deviations, and ANOVA results are presented in Table 3. Analyses revealed a main effect for mode of administration, with participants in the interview condition being significantly more likely than either computer or questionnaire participants to prefer another mode of administration. Likewise, questionnaire participants reported a greater preference for another mode than did computer participants. Computer participants expressed the lowest preference for another condition, implying that they were more satisfied than questionnaire or interview participants with their assigned mode of administration. Although no main effect was found for victim status, a significant interaction was identified between victim status and mode of administration such that, in the interview condition, victims reported a greater preference than did nonvictims for a condition other than their own. By contrast, in the questionnaire and computer conditions, preference for another condition was equivalent for victims and nonvictims (LSD minimum mean difference $=0.34$ ). Thus, victim status was only related to increased preference for another condition for victims in the interview condition.

\section{Effect of Victim Status and Mode of Administration on Perception of Confidentiality}

Finally, as noted, participants were asked whether they felt that the information they provided on the CAMI would be kept confidential $(1=$ strongly disagree to $5=$ strongly agree $)$. Overall means indicated that participants generally perceived that their responses would remain private $(M=4.3, S D=.85)$.

To examine the effects of victim status (victim and nonvictim) and mode of administration (interview, questionnaire, and computer) on participants' perception of confidentiality, a between-groups factorial ANOVA with follow-up analyses using the LSD procedure $(p=.05)$ was performed. The means and standard deviations for all groups, as well as the ANOVA results, are presented in Table 4. These analyses revealed a main effect for victim status, with victims reporting lower confidence in the confidentiality of their responses, $F(1,320)=9.72, p$ $<.01$. In addition, a main effect for mode of administration was identified, $F(2,320)=22.87$, $p<.01$. Post hoc analyses found that participants in the computer condition felt that their information was more confidential than participants in the questionnaire or interview conditions, which were equivalent (LSD minimum mean difference $=0.28$ ). There was no significant interaction between victim status and mode of administration in terms of participants' perception of confidentiality.

\section{DISCUSSION}

The present study used an experimental design to evaluate the impact of three modes of assessment on participant responses to a child maltreatment survey. We found that administration format was statistically unrelated to the likelihood of disclosing either child sexual or physical abuse. Although these findings indicate that assessment format has little impact on 


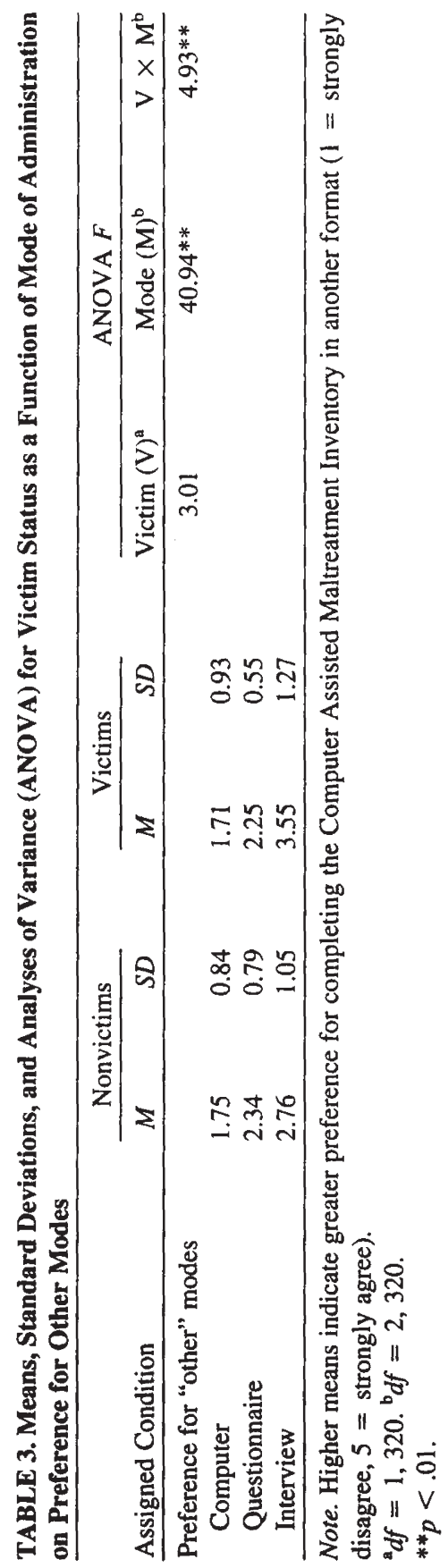


willingness to disclose, past research comparing reporting rates of other sensitive behaviors (e.g., adolescent sexual activities) have found that a computer format elicits greater reporting (e.g., Turner et al., 1998). However, given that there was sufficient statistical power to detect differences in the present sample, it may be that the reporting of sexual and physical abuse history is relatively less impacted by assessment mode than are other sensitive topics, at least in a college sample. One notable finding was that a sizable number of participants with a history of abuse reported distress - either perceived mood change or upset-associated with the assessment. It is difficult to compare these results with past work because prior studies have examined distress in different ways - for example, by assessing unexpected upset (Newman et al., 1999; Walker et al., 1997) or by asking whether subjects regretted participating (Walker et al., 1997). The fact that participants did not reveal distress during interviews or debriefing encounters suggests that the discomfort reported on the feedback questionnaire may have been more mild and fleeting than severe or lasting. Supporting this possibility is our finding that mean distress ratings, even among those with the highest distress (victims in the computer condition) fell into the neutral response range. These results are consistent with past research showing that only a small proportion of abuse victims become seriously upset by participation in trauma-related research (Walker et al., 1997). In fact, recent data from college students suggest that distress evoked by trauma research may be no greater than that encountered in everyday life (DePrince \& Freyd, 2004).

Several findings emerged regarding the relative reactions between groups to the assessment. For example, in comparison to nonvictims, those with a history of abuse reported greater upset and mood change after completing the CAMI. Such differences may stem from discomfort that victims experience in the process of recalling unpleasant memories of abuse. The design of the CAMI, which presents only those who endorse abuse screeners with sensitive follow-up questions about their maltreatment experiences, may also have contributed to these differences. It is difficult to determine why victims in the computer condition reported more distress than victims in other conditions. Perhaps greater familiarity with paper-and-pencil measures or a sense of emotional support conveyed by interviewers helped participants in these conditions feel relatively more at ease.

Responses to items about preferred assessment formats suggested that, regardless of victim status, those in the computer condition were most satisfied with their own mode of administration, followed by individuals completing the questionnaire, and lastly by those in the interview condition. Preferences for the computer assessment may have resulted from the absence of complex instructions afforded by this mode of administration. These preferences are also consistent with perceptions of greater confidentiality associated with computer administration. In contrast to these results were findings that, among those in the interview condition, abuse survivors reported a strong preference for a different mode of administration. However, although survivors reported relatively less belief in the confidentiality of the assessments, their mean scores, particularly in the computer condition, suggest a general feeling that information would be kept confidential. These findings contrast somewhat with those noted above, that the computer assessment was more distressing for those with a history of abuse. Thus, even though victims were more emotionally impacted by the computer assessment, they prefer that format and view it as a confidential means of disclosing personal abuse history.

The limitations of the present study highlight several directions for additional research. First, future work should include larger and more representative samples. In particular, be- 


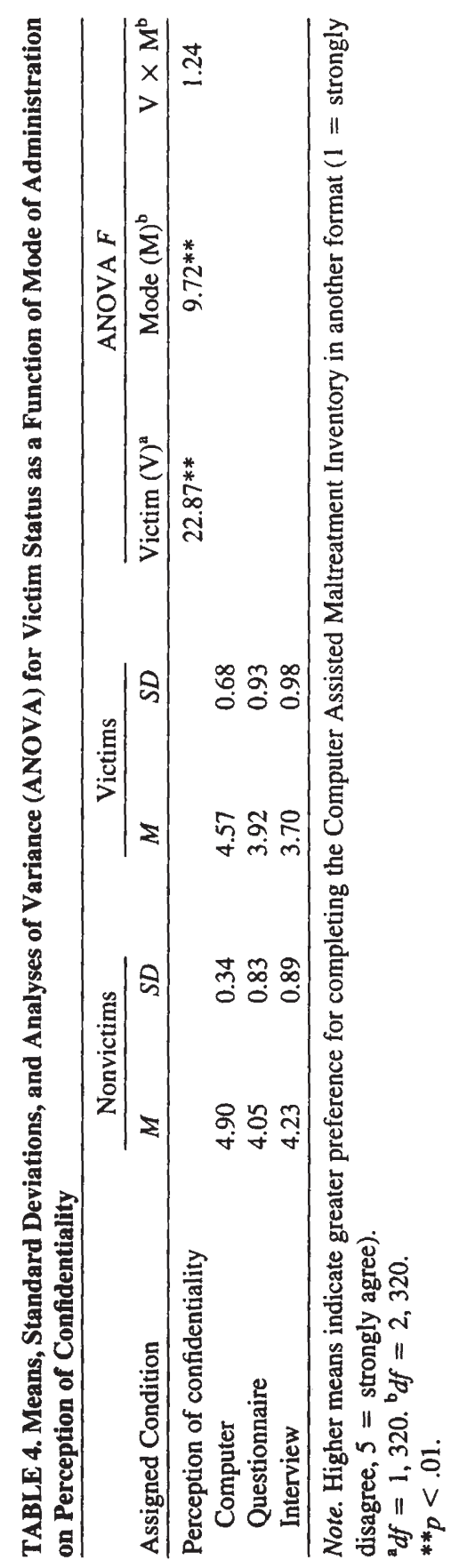


cause most studies have focused on nonminority women, efforts should be made to include male participants and those from diverse ethnic backgrounds. Relatedly, it would be useful to explore individual difference variables such as age, ethnicity, and facility with computers, which may be related to outcomes such as disclosure rates, emotional distress, and perceptions of confidentiality. In addition, because distress in the current study was assessed at post-assessment only, we have no way of knowing whether the subgroups reporting abuse were more upset prior to the assessment. Thus, it would be advantageous to incorporate pre-and post-assessment measures of mood state to provide a more psychometrically sound measure of the emotional impact of participation. Finally, future studies should compare the emotional impact of abuse history surveys to that associated with the assessment of other sensitive topics, such as domestic violence, abortion, and substance use. These efforts can add perspective to the impact of abuse history studies relative to other common areas of research.

Despite its limitations, the present study has important implications for abuse history research. First, although average distress levels were low, it was found that a subset of individuals, especially those with a history of childhood abuse, experience some degree of upset associated with their participation in abuse surveys. This finding highlights the need to have an informed consent process that clearly alerts participants to the risks of involvement and the right to skip questions or discontinue participation at any time. Further, debriefings should include specific inquiries about emotional reactions to assessments as well as written referral information for all participants, in the event of delayed adverse reactions. Follow-up calls should be made to those who express any distress at the time of the assessment. Finally, although maintaining confidentiality is important in any investigation, this principle is especially crucial to those assessing child maltreatment experiences. Breaking confidentiality could be viewed as a betrayal of trust, an issue that may be particularly salient for those with a history of abuse. It is through steps such as these that abuse history research can be conducted most sensitively and in a manner that maximizes protection of human subjects.

\section{REFERENCES}

Abbey, A., BeShears, R., Clinton-Sherrod, A. M., \& McAuslan, P. (2004). Similarities and differences in women's sexual assault experiences based on tactics used by the perpetrator. Psychology of Women Quarterly, 28, 323-332.

Aquilino, W. S. (1994). Interview mode effects in surveys of drug and alcohol use: A field experiment. Public Opinion Quarterly, 58, 210-240.

Carlson, E. B., Newman, E., Daniels, J. W., Armstrong, J., Roth, D., \& Loewenstein, R. (2003). Distress in response to and perceived usefulness of trauma research interviews. Journal of Trauma \& Dissociation, 4(2), 131-142.

DePrince, A. P., \& Freyd, J. J. (2004, August). A harmful taboo? Addressing fear of harm in asking participants about history. Paper presented at the annual meeting of the American Psychological Association, Honolulu, HI.

Fry, R.P.W., Rozewicz, L. M., Crisp, A. H. (1996). Interviewing for sexual abuse: Reliability and effect of interviewer gender. Child Abuse and Neglect, 20, 725-729.

Kissinger, P., Rice, J., Farley, T., Trim, S., Jewitt, K., Margavio, V., \& Martin, D. H. Application of computer-assisted interviews to sexual behavior research. American Journal of Epidemiology, 149, 950954. 
Lessler, J., \& Holt, M. (1987). Using response protocols to identify problems in the U.S. census long form. Proceedings of the Survey Research Section of the American Statistical Association. Washington, DC: American Statistical Association.

Maitland, M. E., \& Mandel, A. R. (1994). A client-computer interface for questionnaire data. Archives of Physical Medicine and Rehabilitation, 75, 639-642.

Martin, J. L., Anderson, J. C., Romans, S. E., Mullen, P. E., \& O’Shea, M. (1993). Asking about child sexual abuse: Methodological implications of a two stage survey. Child Abuse and Neglect, 17, 383392.

Martin. J. L., Perrott, K., Moms, E. M., \& Romans. S. E. (1999). Participation in retrospective child sexual abuse research: Beneficial or harmful? What women think six years later. In L. M. Williams, V. L. Banyard, et al. (Eds.), Trauma \& memory (pp. 149-159). Thousand Oaks, CA: Sage.

Nash, C. L., DiLillo, D., Messman-Moore. T. L., \& Rinkol, S. (2002, November). The Computer Assisted Maltreatment Inventory (CAMI): An investigation of test-retest reliability and criterion validity. Paper presented at the meeting of the Association for the Advancement of Behavior Therapy, Reno, NV.

Newman, E., Walker, E. A., \& Gefland, A. (1999). Assessing the ethical costs and benefits of focused research. General Hospital Psychiatry, 21, 187-196.

Rind, B., Tromovitch, P., \& Bauserman, R. (1998). A meta-analytic examination of assumed properties of child sexual abuse using college samples. Psychological Bulletin, 124, 22-53.

Schober, S. E., Fe Caces, M., Pergamit, M. R., \& Branden, L. (1992). Effect of mode of administration on reporting of drug use in the National Longitudinal Study. In C. F. Turner, J. T. Lessler, \& J. C. Gfroerer (Eds.), Survey measurement of drug use: Methodological studies (pp. 267-276). Rockville, MD: National Institute on Drug Abuse.

Tourangeau, R., \& Smith, T. W. (1996). Asking sensitive questions: The impact of data collection mode, question format, and question context. Public Opinion Quarterly, 60, 275-304.

Turner. C. F., Ku, L., Rogers. S. M., Lindberg, L. D., Pleck, I. H., \& Sonenstein, F. L. (1998). Adolescent sexual behavior, drug use, and violence: Increased reporting with computer survey technology. Science, 280, 867-873.

Turner, C. F., Lessler, J. T., \& Devore, G. (1992). Effects of mode of administration and wording on reporting of drug use. In C. F. Turner, J. T. Lessler, \& J. C. Gfroerer (Eds.), Survey measurement of drug use: Methodological studies (pp. 177-220). Rockville, MD: National Institute on Drug Abuse.

Walker, E., A., Newman, E., Koss, M. P., \& Bernstein, D. (1997). Does the study of victimization revictimize the victims? General Hospital Psychiatry, 19, 403-410.

Williams, L. M. (1994). Recall of childhood trauma: A prospective study of women's memories of child sexual abuse. Journal of Consulting and Clinical Psychology, 62, 1167-1176.

Wyatt, G. E., \& Peters, S. D. (1986). Methodological considerations in research on the prevalence of child sexual abuse. Child Abuse and Neglect, 10, 241-251.

Acknowledgments. This study was supported by a grant from the University of Nebraska-Lincoln Research Council. The authors would like to thank John Clemmons, who coordinated data collection, as well as the numerous research assistants who contributed to this project. 